\title{
The Use of Concentrated Heat Stream to Repair AlZn10Si8Mg Alloy Castings
}

\author{
Mirosław Tupaj ${ }^{1}$, Andrzej Trytek ${ }^{1}$, Karol Lysiak ${ }^{1}$, Wiktoria Zbyrad-Kołodziej ${ }^{1}$, Andrzej Laczek $^{1}$, Jan Majernik ${ }^{2}$ \\ ${ }^{1}$ Rzeszow University of Technology, The Faculty of Mechanics and Technology, Stalowa Wola 37-450, Kwiatkow- \\ skiego 4, Poland. Email: mirek@prz.edu.pl \\ 2The Department of Mechanical Engineering, Faculty of Technology Institute of Technology and Business in \\ České Budějovice, Okružní 517/10, 37001 České Budějovice, Czech Republic.
}

The present paper discusses the possibility to use three different sources of concentrated heat stream to repair superficial defects on AlZn10Si8Mg alloy castings. Simulated defects were prepared on specimens taken from a production casting made with the use of low-pressure casting method. The energy sources used to repair the defect were those known as MIG/MAG, TIG, and ML (micro-laser) methods. As the filler, a AlSi5 welding wire was used. The quality of repair was assessed based on both destructive and non-destructive testing. To evaluate porosity of the performed overlay welds, the computer $\mathrm{X}$-ray tomography technique was employed. Metallographic examination was used to assess macro- and micro-structure of overlay welds, measure geometrical parameters of the welds and the heat-affected zone, and determine values of SDAS microstructure parameter. Hardness of overlay welds and the casting material was measured with the use of Brinell hardness machine.

Keywords: $\mathrm{Al}$ alloy, defects in castings, concentrated heat stream, computer tomography, metallographic tests

\section{Introduction}

The AlZn10Si8Mg alloy is a new-generation material used to manufacture castings which are characterized with satisfactory mechanical properties and do not need any costly heat treatment as their mechanical properties increase as a result of natural aging consisting in keeping at ambient temperatures for 7-10 days $[1,2]$. The alloy gains increasing popularity in the automotive industry where it is used for components working in variable load conditions and drives the AlSi7Mg alloy used earlier for such applications out of the business [3], wherever the castings are expected to show high fatigue strength which is affected by microstructure, non-metallic inclusions, and porosity. Some authors [4-7] claim that fatigue cracks in castings of aluminum-silicon alloys, i.e. in the group of materials among which the AlZn10Si8Mg alloy is numbered, nucleating in material discontinuities occurring in its superficial region, play the key role in the structural destruction mechanism.

In the process of manufacturing castings of nonferrous metal alloys, superficial defects such as porosity, cracks, misruns, and cavities are typically repaired with the use of MIG (metal inert gas) and TIG (tungsten inert gas) electric arc welding methods [8] and laser welding [9]. In view of high solubility of hydrogen in liquid metal and virtually no solubility in the solid state matter, as a result of high heat concentration, blowholes may appear in overlay welds. That can be a significant problem in case of application of welding methods which are characterized with high concentration of heat. In view of the above, the objective of the study presented in this paper was to examine the rationale behind the use of one of three sources of concentrated stream of heat, namely MIG welding, TIG welding, and ML (micro-laser) welding characterized with different degree of heat stream concentration, but in any case with the use of the same AlSi5 filler, for repairing defects in $\mathrm{AlZn} 10 \mathrm{Si} \mathrm{Mg} 0.3$ alloy castings.

\section{Experimental}

The tests were carried out on samples taken from a production $\mathrm{AlZn} 10 \mathrm{Si} 8 \mathrm{Mg} 0.3$ alloy casting fabricated with the use of low-pressure casting method. Chemical composition of the used AlZn10Si8Mg0.3 alloy is detailed in Table 1.

Tab. 1 Chemical composition of a production casting cast of AlZn10Si8MgO. 3 alloy

\begin{tabular}{|l|l|l|l|l|l|l|l|l|}
\hline Element & $\mathrm{Zn}$ & $\mathrm{Si}$ & $\mathrm{Mg}$ & $\mathrm{Fe}$ & $\mathrm{Ti}$ & $\mathrm{Sr}$ & $\mathrm{Ni}$ & $\mathrm{Al}$ \\
\hline Content (\% wt.) & 9.25 & 9.21 & 0.32 & 0.12 & 0.14 & 0.03 & 0.01 & to bal. \\
\hline
\end{tabular}

On three samples, three grooves were made, each 40-mm long, 1.3-mm deep, and 3-mm wide. The damaged surface was then repaired with the use of multi- function welding device Speedtec 405SP equipped with PF46 digital wire feeder (Lincoln Electric). The applied welding techniques were MIG method, TIG 
method, and ML method for which semi-manual SWA 300 laser system (SISMA) was used.

Parameters of the process of repairing the simulated casting defect were optimized based on visual examination of the performed overlay welds. In case of MIG method, electric current with intensity $I=175 \mathrm{~A}$ and voltage $U=24 \mathrm{~V}$ was used, at the filler wire feeding rate of $7.5 \mathrm{~m} / \mathrm{min}$ and the shield gas (Argon 5.0) supply rate of $14 \mathrm{l} / \mathrm{min}$. Parameters of welding with the use of TIG method were as follows: electric current intensity $I=180 \mathrm{~A}$ at voltage $U=19 \mathrm{~V}$; the shield gas (Argon 5.0) supplied at the rate of $12 \mathrm{l} / \mathrm{min}$; and the tungsten electrode diameter $d=2.4 \mathrm{~mm}$. When the micro-laser welding method was used, the laser pulse was generated at $32 \%$ of the maximum power, with the pulse duration $t=5.9 \mathrm{~ms}$, pulse repetition frequency of $5 \mathrm{~Hz}$, pulse energy of $18.6 \mathrm{~J}$, laser beam diameter of $0.8 \mathrm{~mm}$, and the shield gas (Argon 5.0) supply rate of $15 \mathrm{l} / \mathrm{min}$. In each of the concentrated heat sources, AlSi5 wire was used as the filler chemical composition of which is listed in Table 2. The wire diameter varied depending on the method used and was $1.2 \mathrm{~mm}$ for MIG method, $2.4 \mathrm{~mm}$ for TIG method, and $0.4 \mathrm{~mm}$ for ML method.

Tab.2 Chemical composition of AlSis wire

\begin{tabular}{|l|l|l|l|l|l|l|l|l|}
\hline Element & $\mathrm{Si}$ & $\mathrm{Fe}$ & $\mathrm{Cu}$ & $\mathrm{Mn}$ & $\mathrm{Mg}$ & $\mathrm{Zn}$ & $\mathrm{Ti}$ & $\mathrm{Al}$ \\
\hline Content (\% wt.) & 5.5 & 0.27 & 0.18 & 0.05 & 0.04 & 0.09 & 0.14 & to bal. \\
\hline
\end{tabular}

From the prepared samples, specimens containing overlay welds with the length of $23 \mathrm{~mm}$ each were cut out for the purpose of examination with the use of computer tomography. Examination of the specimens was carried out with the use of X-ray computer tomograph phoenix $\mathrm{v} \mid$ tome $\mid \mathrm{x} \mathrm{m}$ equipped with direct beam $\mathrm{X}$-ray tube offering the operating voltage range $10-300 \mathrm{kV}$ at the operating current intensity in the range 5-3000 $\mu \mathrm{A}$. The following $\mathrm{X}$-ray scanning parameters were used: $\mathrm{X}$-ray tube voltage $-250 \mathrm{kV}$; tube current intensity $-190 \mu \mathrm{A}$; single picture exposure time $-500 \mathrm{~ms}$; voxel size $-6 \mu \mathrm{m}$. In the course of scanning, 1000 pictures per specimen were taken and used to reconstruct the image. Analysis of material defects was carried out with the use of VG Studio MAX 2.2 software.

The specimens were then cut in the planes perpendicular to their longitudinal axes to obtain metallographic sections by means of standard grinding and polishing. Macrostructure of the sections was revealed with the use of etching in $4 \% \mathrm{HF}$ solution, whereas microstructure was exposed by using $10 \% \mathrm{NaOH}$ solution. Examination of both macrostructure and microstructure was carried out with the use of Neophot 2 optical microscope equipped with OPTA-TECH RT 16 camera. Measurements of geometry of the overlay welds and width of the heat-affected zone (HAZ) were taken. For both the casting material and the overlay weld material, the structural parameter used to evaluate the microstructure was SDAS - the value of spacing between secondary dendrite arms $\alpha(\mathrm{Al})$, measured with the use of Multiscan v. $18.03 \mathrm{ad}-$ vanced image analysis system. In case of the casting material, $\times 100$ magnification was used to take the measurements, whereas the material of overlay welds was examined under $\times 400$ magnification. Each time, counts were taken on 10 measurement areas with a total of 100 cells analyzed for each area. In the casting material and in overlay welds, hardness HB5 was measured with the use of ERNST brand hardness machine. The indenter was tipped with a steel ball with the diameter of $1 / 6$ inch.

\section{Results}

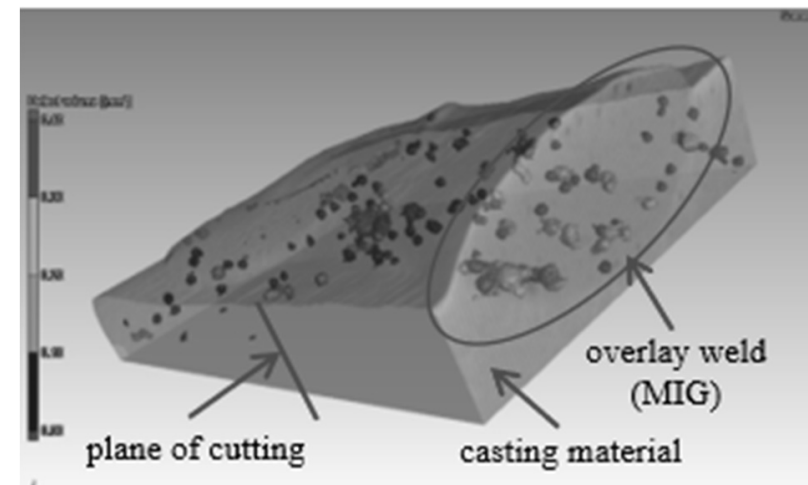

a)

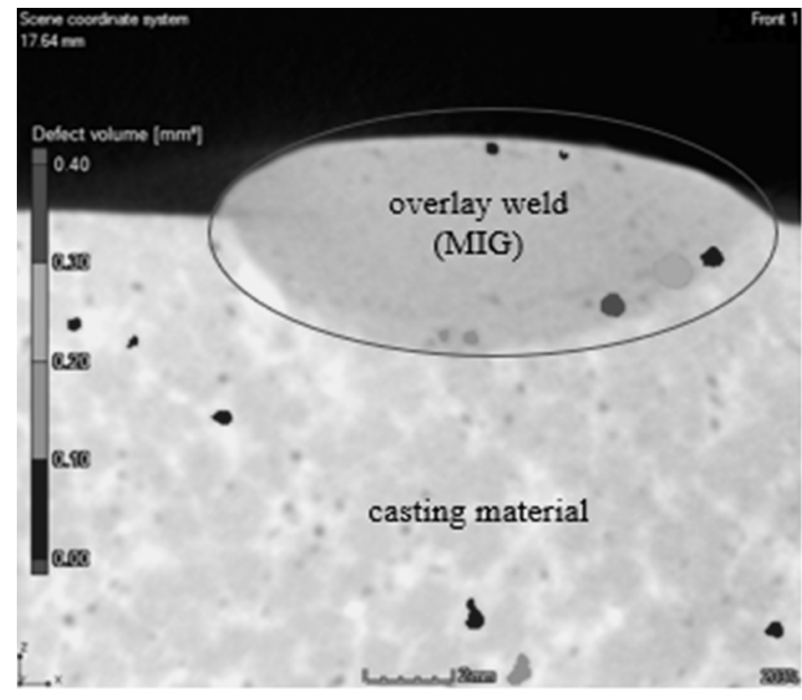

b)

Fig. 1 Results of tomographic examination of AlZn10Si8Mg0.3 alloy casting areas with simulated casting defect repaired with the use of MIG method; (a) 3 D view; (b) transverse cross-section 


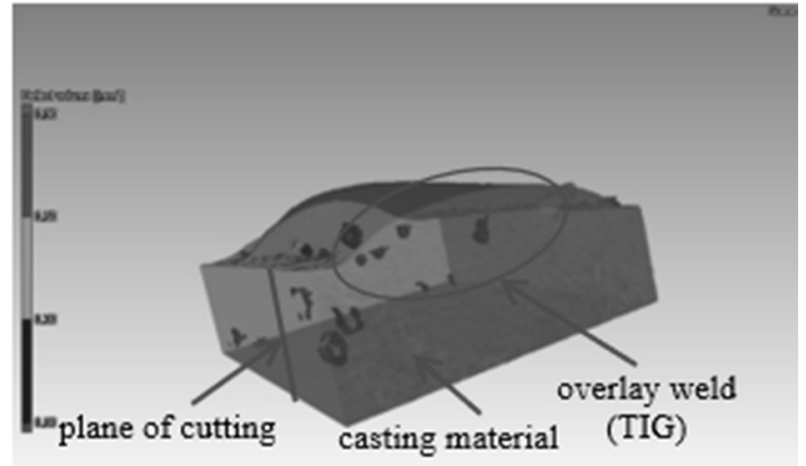

a)

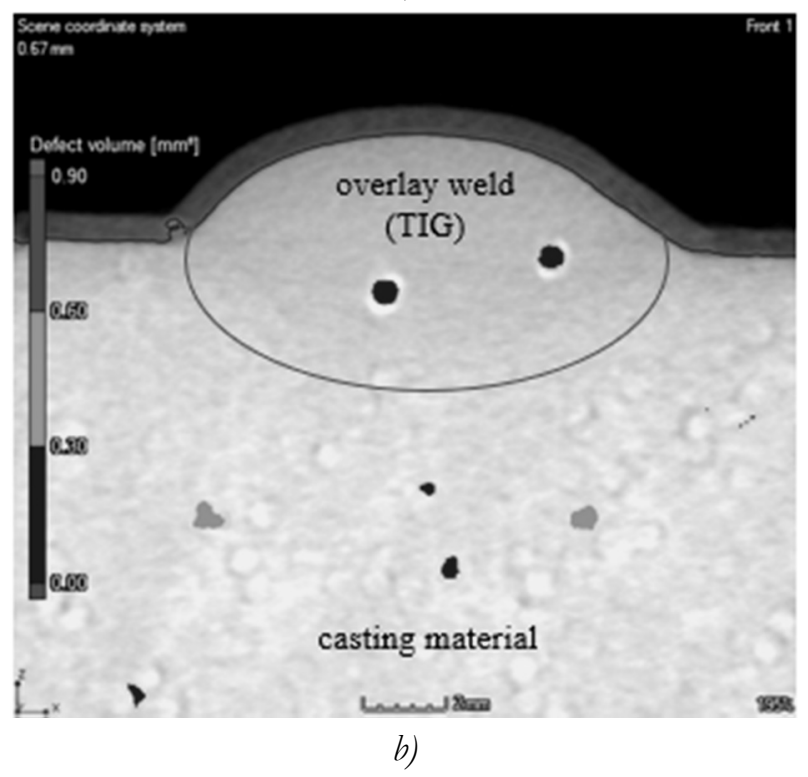

Fig. 2 Results of tomographic examination of AlZn10Si8Mg0.3 alloy casting areas with simulated casting defect repaired with the use of TIG method; (a) 3 D view; (b) transverse cross-section

Results of tomographic examination (3D views and transverse cross-section) of $\mathrm{AlZn} 10 \mathrm{Si} 8 \mathrm{Mg} 0.3 \mathrm{al}-$ loy casting areas where simulated defects were repaired with the use of MIG, TIG, and micro-laser
(ML) methods, are presented in Figures 1-3. Table 3 and Figure 4 present results of tomographic examination revealing pores occurring in specimens of overlay welds.

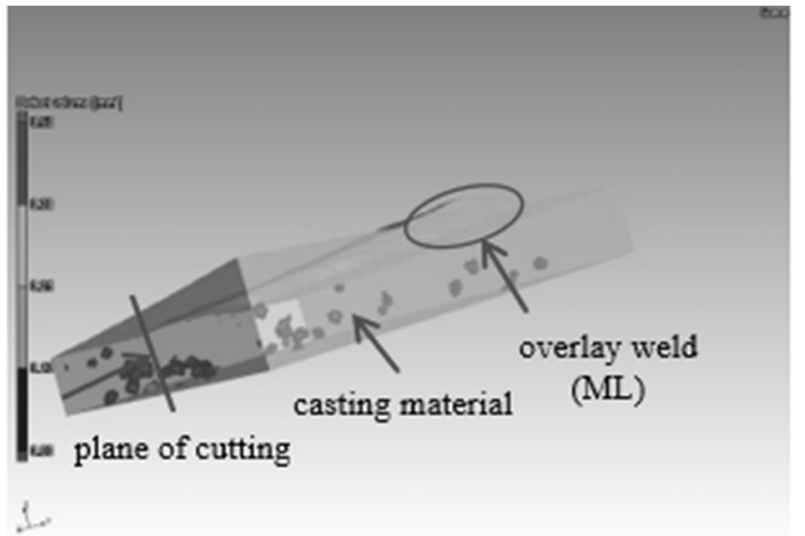

a)

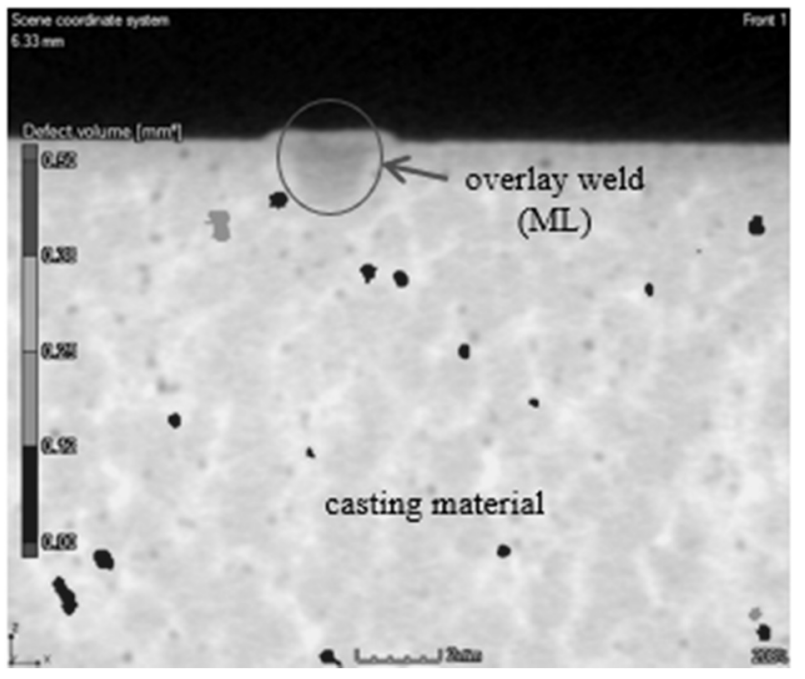

b)

Fig. 3 Results of tomographic examination of AlZn10Si8Mg0.3 alloy casting areas with simulated casting defect repaired with the use of ML method; (a) 3D view; (b) transverse cross-section

Tab. 3 Results of tomographic examination of defects occurring in overlay welds made with the use of MIG, TIG, and ML method

\begin{tabular}{|c|c|c|c|}
\hline Repair method & $\begin{array}{c}\text { Number of pores in overlay } \\
\text { weld specimen }\end{array}$ & $\begin{array}{c}\text { Average pore diam- } \\
\text { eter, } \mathrm{mm}\end{array}$ & Pore diameter spread range, mm \\
\hline MIG & 48 & 0.83 & $0.42-2.97$ \\
\hline TIG & 8 & 1.03 & $0.72-1.91$ \\
\hline ML & none & - & - \\
\hline
\end{tabular}

Results of the tests indicate that the material of the casting fabricated with the use of low-pressure casting method is characterized with a significant porosity. In case of the overlay weld material, the highest porosity was demonstrated by the overlay weld made with the use of MIG method in which presence of 48 pores was found in the specimen. Much less population of pores, namely 8 , characterized the overlay weld made with the use of TIG method. Ultimately it turned out the overlay weld made with the use of micro-laser
(ML) technique had no visible pores at all. Analysis of pore dimensions revealed that in case of the overlay weld made with the use of MIG method, the average of pore diameters was $0.83 \mathrm{~mm}$ and varied within the range from $0.42 \mathrm{~mm}$ to $2.97 \mathrm{~mm}$. In the overlay weld made with the use of TIG method, the mean pore diameter was $1.03 \mathrm{~mm}$, but pore sizes varied within a significantly narrower range, namely from $0.72 \mathrm{~mm}$ to $1.91 \mathrm{~mm}$. To sum up that portion of research results it should be emphasized that the difference in porosity 
observed in overlay welds made with the use of MIG method and TIG method is a result of better stability of the welding process in case of the latter.
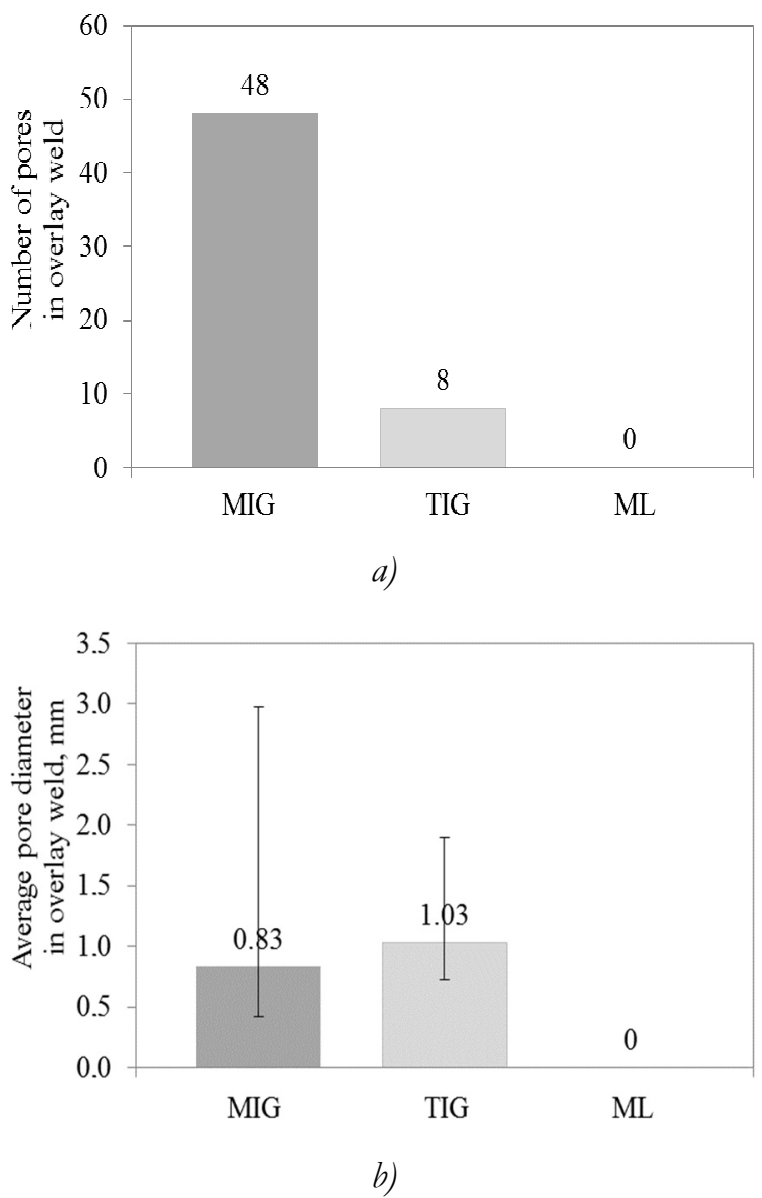

Fig. 4 Results of tomographic examination of defects occurring in overlay weld specimens: (a) number of pores in overlay welds; (b) average pore diameter in overlay welds

Figure 5 shows example views of macrostructure observed in AlZn10Si8Mg0.3 alloy casting areas after the process of repairing simulated casting defects with the use of MIG, TIG, and ML method.

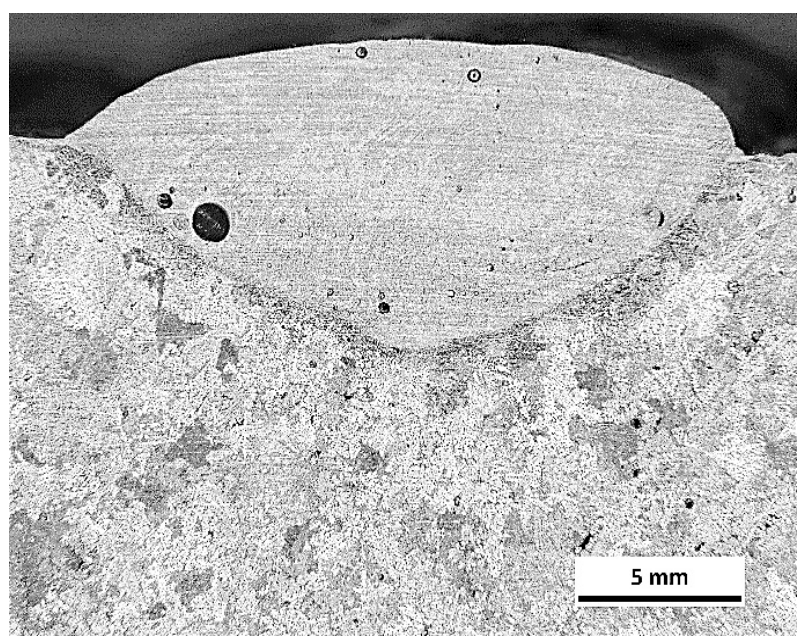

a)

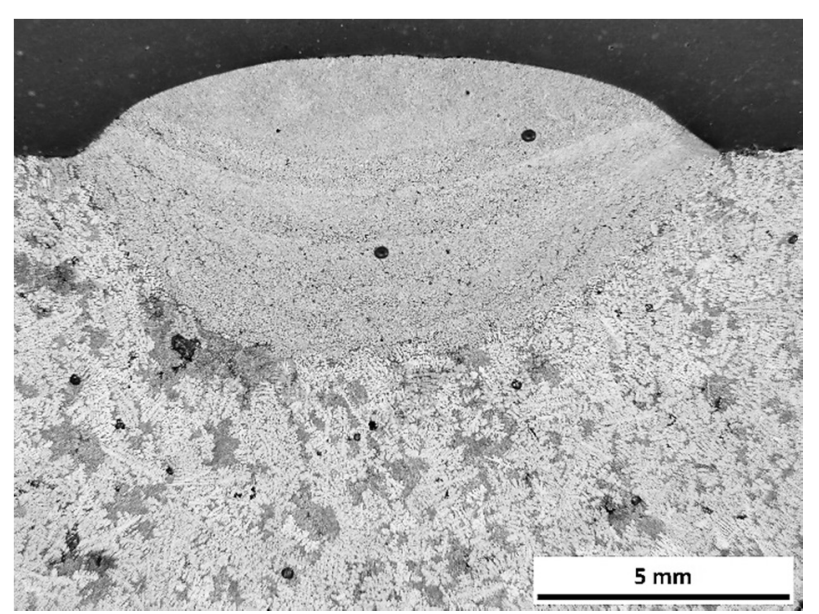

b)
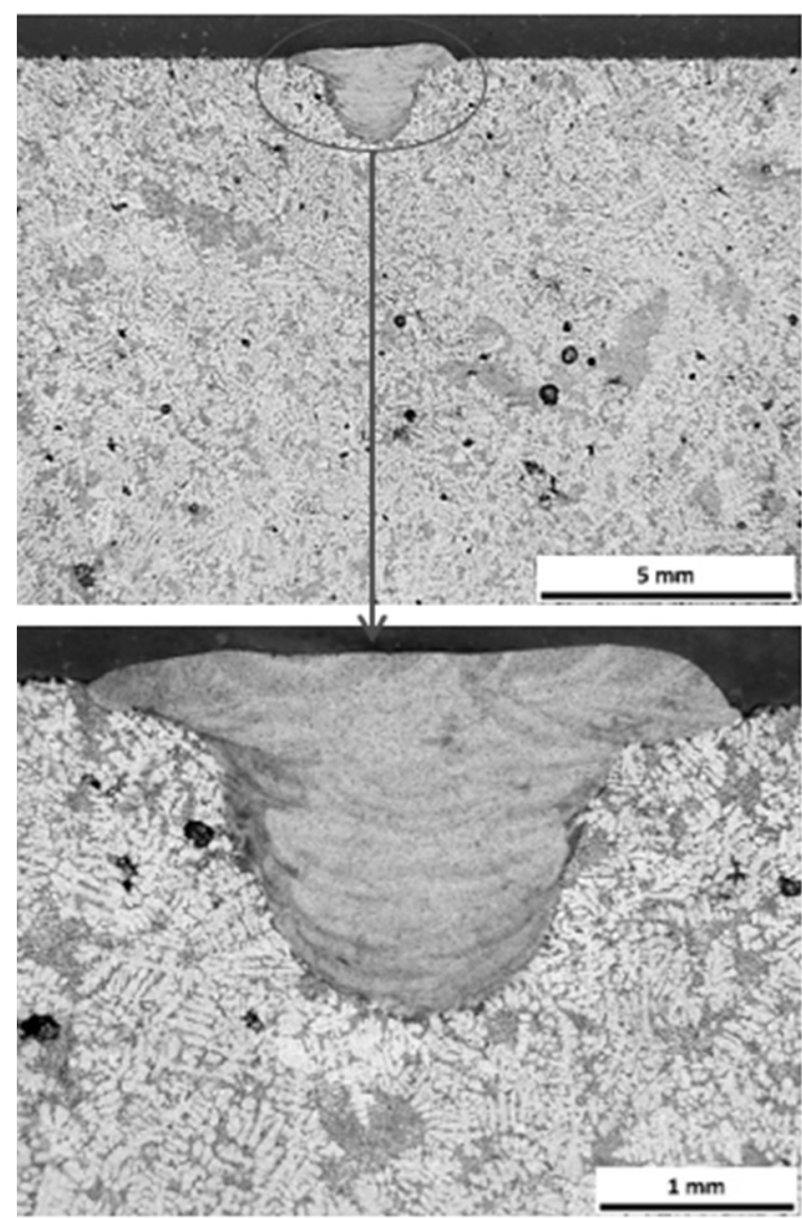

c)

Fig. 5 Example views of macrostructure of AlZn10Si8MgO.3 alloy casting areas with a simulated casting defect repaired with the use of: (a) MIG method; (b) TIG method; and (c) ML method

Results of microscopic examination are consistent with images and measurements obtained with the use of X-ray tomography. The highest porosity characterizes the overlay weld made with the use of MIG method. The pores are characterized with large size, reaching the diameter of up to $3 \mathrm{~mm}$. In case of the 
overlay weld made with the use of TIG method, the void fraction and pore diameters were significantly less. In overlay welds made with the use of ML method, no porosity at all was observed.

Results of measurements of the geometry of overlay welds and the width of the heat affected zone (HAZ) are given in Figure 6.

Overlay weld geometry parameters, $\mathrm{mm}$

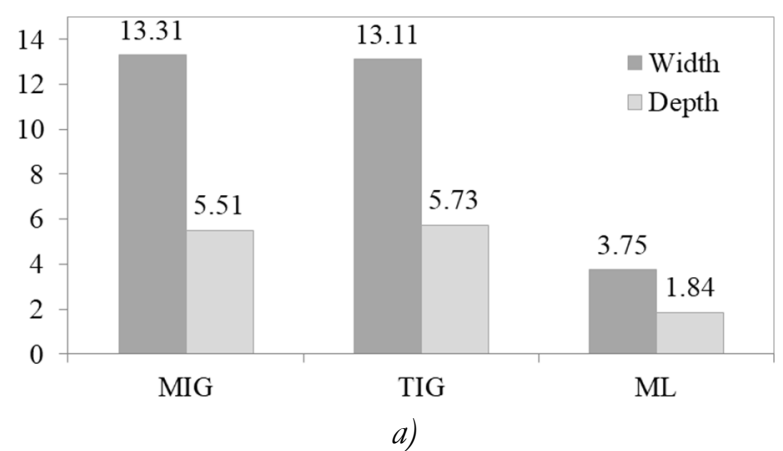

HAZ width, mm

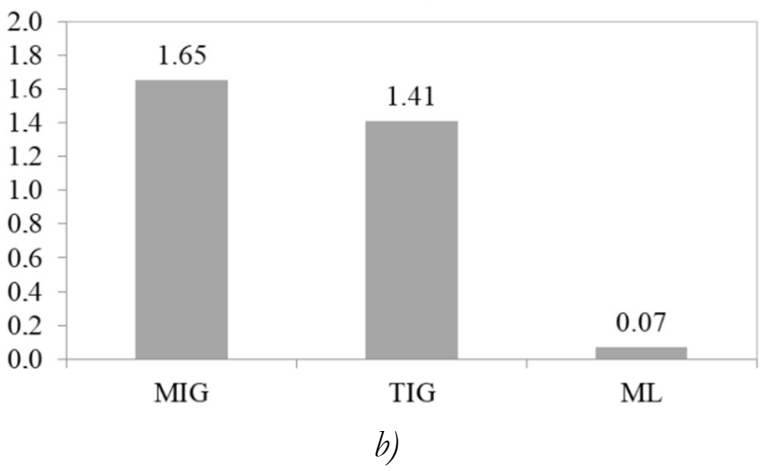

Fig. 6 The effect of casting repair method on: (a) overlay weld geometry; (b) $\mathrm{HAZ}$ width

Results of the research indicate that when either MIG or TIG method is applied, the geometry of overlay welds is similar. It turned out that dimensions of overlay welds are more than four times greater than dimensions of the simulated casting defect. Application of ML method enabled to repair the simulated defect by filling it precisely. It turned out also that in case of using the micro-laser technique, the heat-affected zone width is more that twenty times less than that obtained when MIG and TIG welding methods were employed.

The microstructure of $\mathrm{AlZn} 10 \mathrm{Si} 8 \mathrm{Mg} 0.3$ alloy castings comprises phase $\alpha$ dendrites, the eutectic $(\alpha+$ Si precipitations), and intermetallics (Figure $7 \mathrm{a}$ ). The material of a casting fabricated with the use of the lowpressure casting method is characterized with presence of porosity (Figure 7b) which manifests in deterioration of mechanical properties of the casting and make it difficult to repair it with the use of welding techniques. Example microstructures from the overlay weld-HAZ area obtained when MIG, TIG, and ML welding methods were used are presented in Figures 8,9 , and 10 , respectively. In the area of overlay weld made with the use of MIG method, numerous pores of diversified size are visible presence of which was revealed by tomographic examination. In the region of overlay weld made by means of TIG technique, significantly less pores were observed characterized with smaller size. In case of the overlay weld made with the use of ML method, no porosity was found.

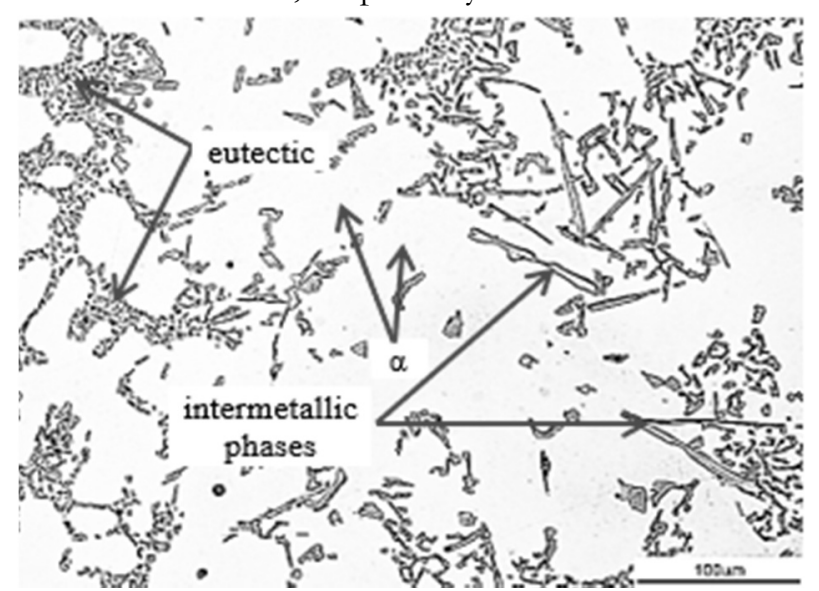

a)

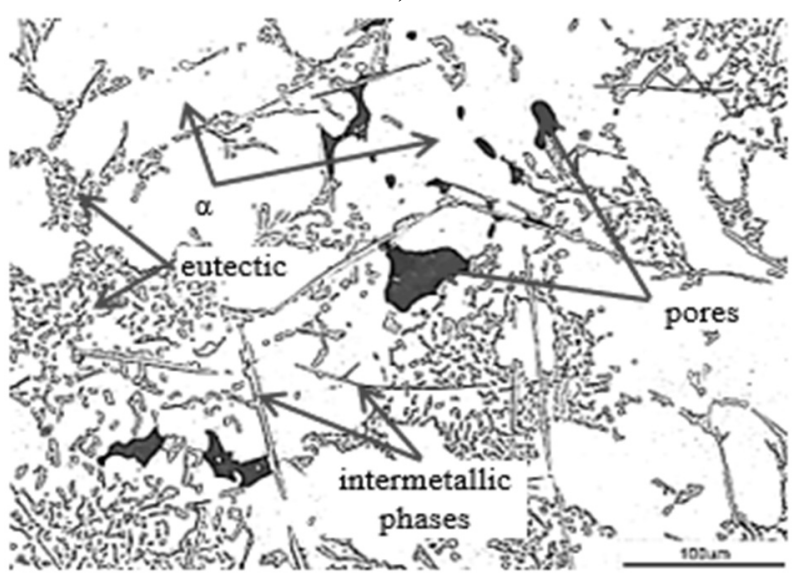

b)

Fig. 7 Example views of AlZn10Si8Mg0.3 casting material microstructure. Etched with $10 \% \mathrm{NaOH}, \times 100$ magnification. Areas (a) free of porosity and (b) with some porosity visible

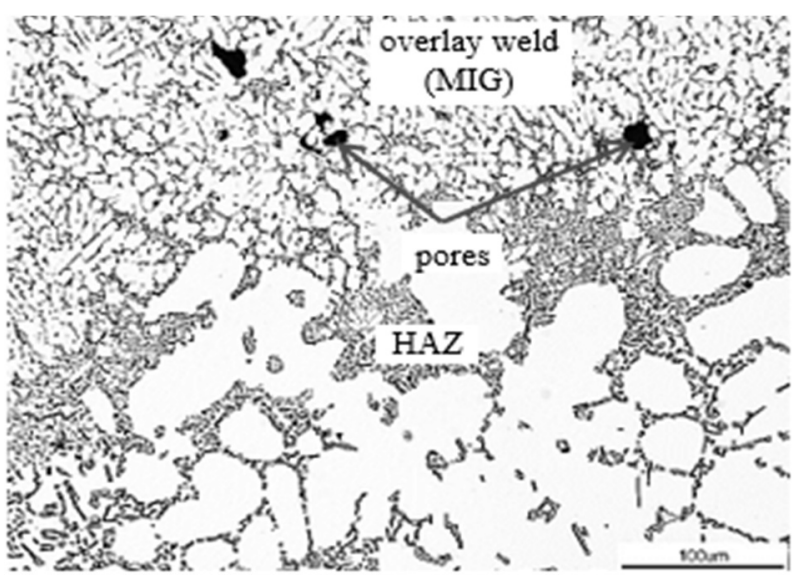

Fig. $\boldsymbol{8}$ Example of microstructure of the areas of simulated casting defect repaired with the use of MIG method. $H A Z$ overlay weld, $\times 100$ magnification. Etched in $10 \% \mathrm{NaOH}$ 


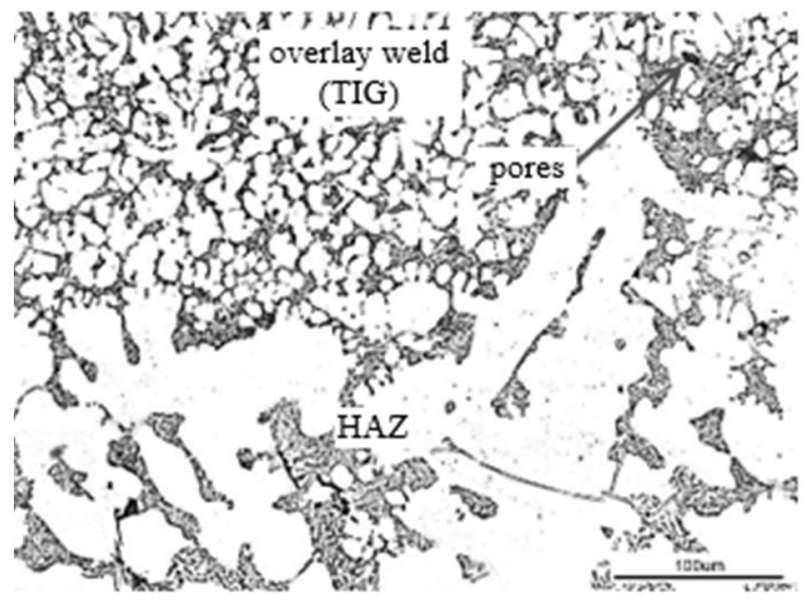

Fig. 9 Example of microstructure of the areas of simulated casting defect repaired with the use of TIG method. HAZoverlay weld, $\times 100$ magnification. Etched in $10 \% \mathrm{NaOH}$

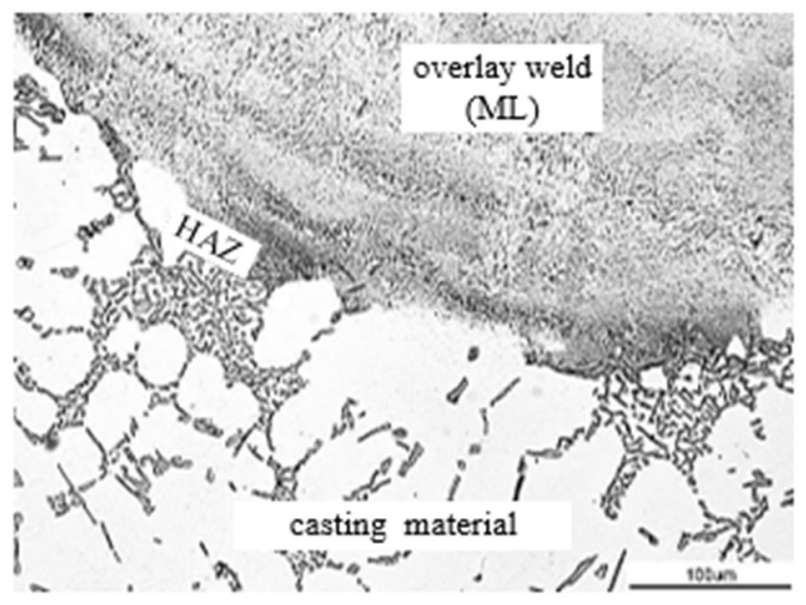

Fig. 10 Example of microstructure of the areas of simulated casting defect repaired with the use of ML method. Casting material-HAZ-overlay weld, $\times 100$ magnification. Etched in $10 \% \mathrm{NaOH}$

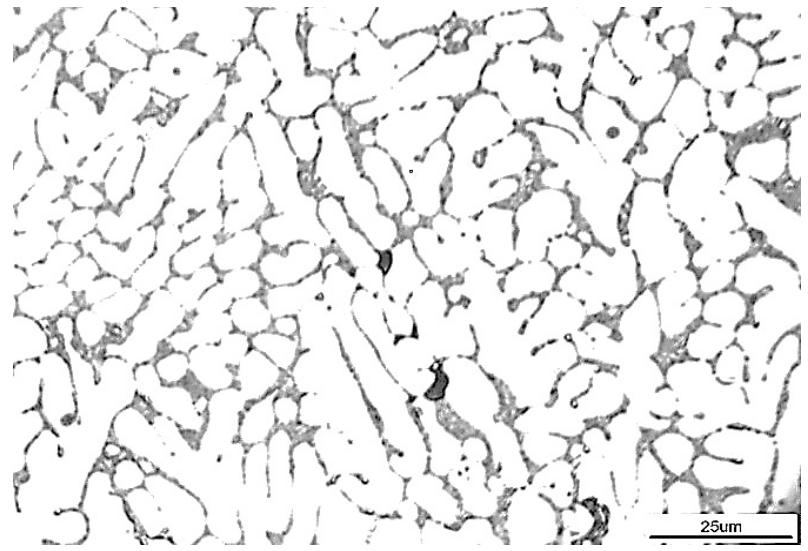

Fig. 11 Example of microstructure of the areas of simulated casting defect repaired with the use of MIG method. Overlay weld, $\times 400$ magnification. Etched in $10 \% \mathrm{NaOH}$

Example microstructures from areas of overlay welds made with the use of MIG, TIG, and ML methods are presented in Figures 11, 12, and 13, respectively. Analysis of the microstructures in individual areas indicates that in the case of the overlay weld made by means of the micro-laser (ML) technique, the highest refinement of phase $\alpha$ dendrites was obtained. That was the effect of rapid crystallization and introduction of the quantity of heat less compared to this required when MIG or TIG methods are used.

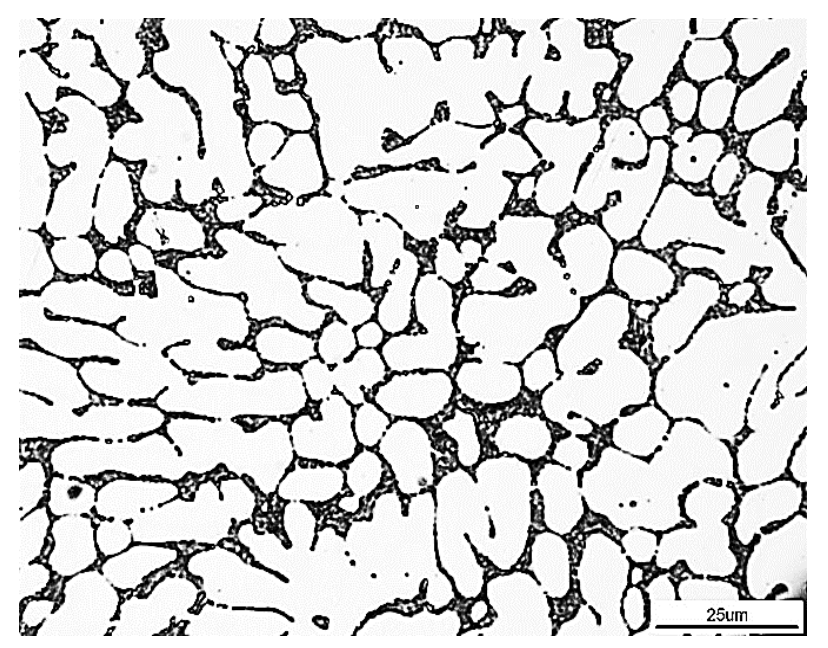

Fig. 12 Example of microstructure of the areas of simulated casting defect repaired with the use of TIG method. Overlay weld, $\times 400$ magnification. Etched in $10 \% \mathrm{NaOH}$

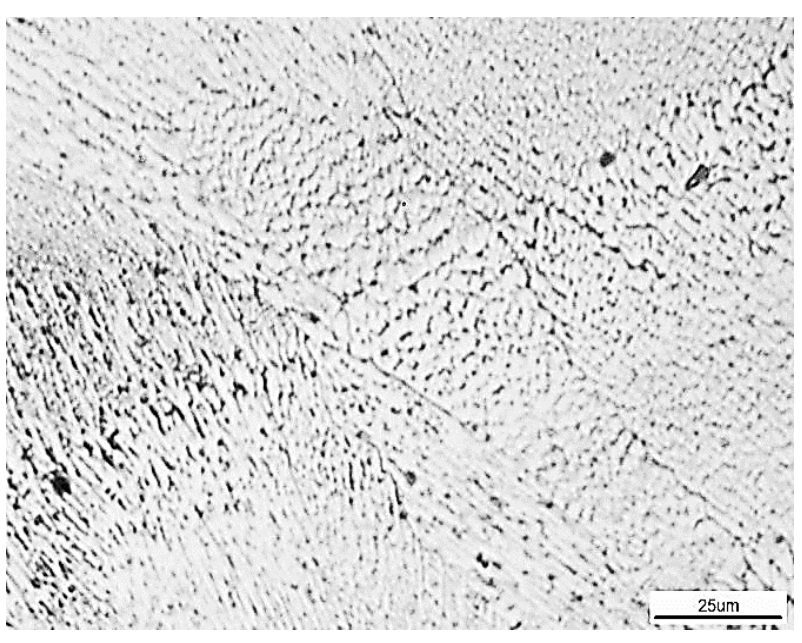

Fig. 13 Example of microstructure of the areas of simulated casting defect repaired with the use of ML method. Overlay weld, $\times 400$ magnification. Etched in $10 \% \mathrm{NaOH}$

SDAS, $\mu \mathrm{m}$

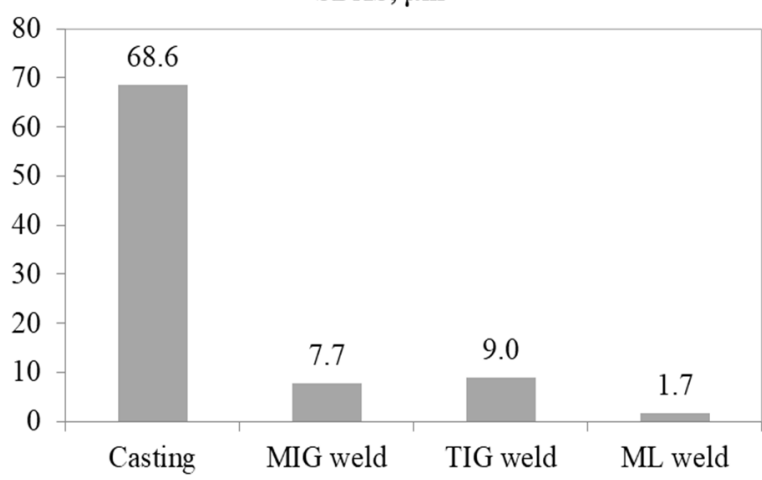

a) 


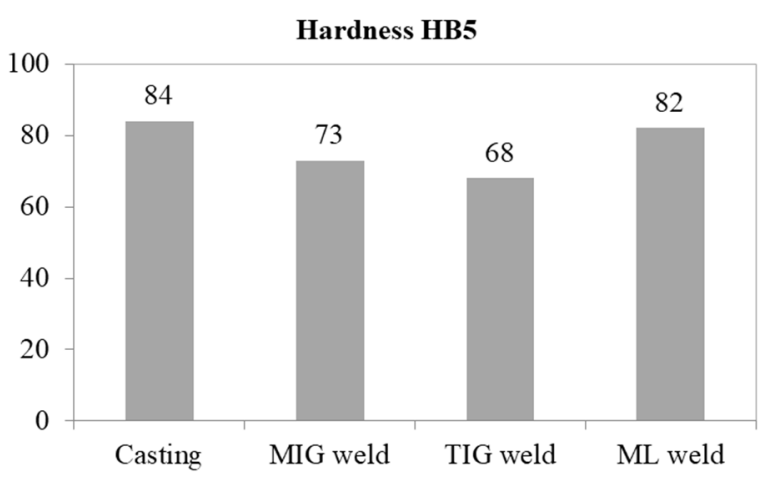

b)

Fig. 14 Results of measurements of (a) SDAS structural parameter and (b) hardness for casting material and the material of overlay welds made with the use of different welding methods

Results of SDAS structural parameter and hardness measurements taken for both the casting material and the material of overlay welds made with the use of welding methods characterized with different intensity of the concentrated heat stream are presented in Figure 14.

Analysis of SDAS structural parameter and hardness measurements indicates that application of MIG method resulted in about 9-fold, the use of TIG method in about 7.5-fold, and employment of ML method in about 40-fold reduction of SDAS parameter value compared to that characterizing the casting material. It turned out that only in case of using the micro-laser method, hardness of the overlay weld was close to that characterizing the casting material. In case of overlay welds made with the use of MIG and TIG method, hardness values of the material were much lower. The observation is all the more essential because no heat treatment processes are applied to AlZn10Si8Mg alloys.

\section{Summary}

- Castings of AlZn10Si8Mg alloys can be effectively repaired with the use of filler in the form of AlSi5 alloy wire and welding methods characterized with different degrees of heat stream concentration.

- Application of either MIG or TIG welding methods which are commonly used to repair aluminum alloy castings, turned out to be unsatisfactory from the point of view of the need to obtain overlay welds characterized with sufficiently low porosity value. That is due to large quantities of heat introduced into the area of repair and tendency of aluminum alloys to catch the gas porosity. As a result, the overlay welds were characterized with dimensions several times larger than those of the repaired nonconformance and hardness values significantly lower compared to the casting material.

- Application of the ML (micro-laser) welding turned out to be the most effective method for repairing superficial casting defects. The technique, characterized with high concentration of heat stream within a small operating area (the fact being evidenced by very small HAZ width) enabled to obtain overlay welds characterized with absence of porosity, a geometry close to that of the repaired nonconformance, and the hardness value close to that of the casting material which is essential because no heat treatment processes are applied to that type of alloy.

\section{Acknowledgements}

The study was carried out with the use of apparatus purchased from funds of the project 'Establishment of the Scientific and Research Inter-University Laboratory in Stalowa Wola', realized as part of the Operational Programme Eastern Poland 2007-2013, Priority axis I 'Modern Economy', Measure 1.3 'Supporting Innovativeness' as per contract No. POPW.01.03.00-18-016/12-00.

The study was performed as part of the contract DS.KO.20.001, Rzeszów University of Technology 2020.

\section{References}

[1] TILLOVÁ E., CHALUPOVÁ M., KUCHARIKOVÁ L., ZÁVODSKÁ D., BELAN J., VAŠKO A. (2016). Use of Microscopy in the Study of Self-Hardening Al-Alloy for Automotive Application. Manufacturing Technology, 16/5, 1174-1179.

[2] ROSSO M., PETER I, CASTELLA C., MOLINA R. (2014). Properties of AlZn10Si8Mg Alloys for High Performances Application. Light Metals, TMS, 2014, 213-218.

[3] VICEN M., FABIAN P., TILLOVÁ. E. (2017). Self Hardening AlZn10Si8Mg Aluminium Alloy as an Alternative Replacement for AlSi7Mg0.3 Aluminium Alloy. Archives of Foundry Engineering, Vol. 17, Issue 3, 139 - 142.

[4] UHRÍČIK M., PALČEK P., CHALUPOVÁ M., ORŠULOVÁ T. (2017). The Structure of the Aluminium Alloy and Its Influence on the 
Fatigue Properties. Manufacturing Technology, Vol. 17, No. 5, 1213-2489. ISSN 1213-2489.

[5] ZÁVODSKÁ D., TILLOVÁ E., GUAGLIANO M., CHALUPOVÁ M., KUCHARIKOVÁ L. (2017). Effects of porosity on the fatigue behaviour of AlZn10Si8Mg casting alloys in a high cycle region. Procedia Engineering 192, 988-993. Doi: 10.1016/j.proeng.2017.06.170.

[6] SERRANO-MUNOZ, I. et al. (2017). Location, location \& size: defects close to surfaces dominate fatigue crack initiation. Sci. Rep.,7, 45239; doi: 10.1038/srep45239.

[7] KUCHARIKOVÁ L, TILLOVÁ E., UHRÍČIK M., BELAN J., ŠVECOVÁ I.
(2017). High-cycles Fatigue of Different Casted Secondary Aluminium Alloy. Manufacturing Technology, Vol. 17, No. 5 , 756-761. ISSN 12132489.

[8] GUPTA Y., TANWAR A., GUPTA R. (2016). Investigation of Microstructure and Mechanical Properties of TIG and MIG Welding Using Aluminium Alloy. IOSR Journal of Mechanical and Civil Engineering. 13. 121-126. DOI: 10.9790/1684-130508121126.

[9] KVASNOVÁ P., DANIEL NOVÁK D., NOVÁK V. (2017). Laser Welding of Aluminium Alloys. (2017). Manufacturing Technology, Vol. 17, No. 6, 892-898. ISSN 1213-2489. 